\title{
Associations between udder health and reproductive performance in United Kingdom dairy cows
}

\author{
C. D. Hudson, ${ }^{1}$ A. J. Bradley, J. E. Breen, and M. J. Green \\ School of Veterinary Medicine and Science, University of Nottingham, Sutton Bonington, LE12 5RD, United Kingdom
}

\begin{abstract}
The objective of this research was to evaluate the relationship between udder health and reproductive performance in UK dairy cows. Data from 80 herds were restructured such that each unit of data represented a 2-d period during lactation where a cow was at risk of becoming pregnant. Multilevel discrete-time survival models were then used within a Bayesian framework to explore associations between reproductive outcomes and a variety of potential explanatory variables. Separate models were constructed using 2 different univariate binary outcomes: a cow becoming pregnant during a risk period and a cow becoming pregnant as a result of a given service. Potential explanatory variables included occurrence of clinical mastitis and a categorical representation of individual cow somatic cell count (SCC), both at a variety of timings relative to the risk period. Posterior predictions were used to assess model fit and to check model building assumptions. These demonstrated that the model represented the data well. Within-sample Monte Carlo simulation (i.e., use of the model to predict outcomes for cases within the data set, repeated over a large number of iterations) was used to illustrate results as posterior predicted relative risks. A negative association was found between reproductive performance and cases of clinical mastitis over a wide time frame relative to the risk period (from $28 \mathrm{~d}$ before to $70 \mathrm{~d}$ after the risk period). A similar negative association with the probability of a service leading to a pregnancy (pregnancy rate) was observed over the same time frame. Higher SCC recordings (i.e., those more likely to be associated with an intramammary infection) were also associated with decreased reproductive performance, especially where an individual cow SCC of greater than $399,000 / \mathrm{mL}$ was recorded in the $30 \mathrm{~d}$ following a risk period or service. This research demonstrates that both clinical and subclinical mastitis are associated with a reduction in reproductive perfor-
\end{abstract}

Received June 17, 2011.

Accepted February 27, 2012.

${ }^{1}$ Corresponding author: chris.hudson@nottingham.ac.uk mance, and that this influence varies in magnitude but can be exerted over a prolonged period.

Key words: reproductive performance, fertility performance, mastitis, dairy cow

\section{INTRODUCTION}

Fertility in dairy cows is a major determinant of herd profitability (Esslemont and Kossaibati, 2002; Esslemont, 2003; González-Recio et al., 2004; LeBlanc, 2007). Fertility in UK dairy herds has been in decline for some time (Esslemont and Kossaibati, 2002; Hudson et al., 2010) and this makes it critical to improve understanding of the factors that influence reproductive performance. This encompasses both herd-level management factors (such as methods of husbandry, feeding, and estrus detection) and individual cow-level factors (such as disease events, milk yield, and genetics). Mastitis is one of the most common clinical disease events in dairy cattle, with the most recent estimate of incidence rate in the UK between 50 and 70 cases per 100 cow-years (Bradley et al., 2007). As a condition associated with inflammation and pain (Kemp et al., 2008), it is reasonable to hypothesize that mastitis may have a negative effect on cow fertility.

In a previous study, Barker et al. (1998) evaluated reproductive performance in dairy cows in a single herd having a case of clinical mastitis (CM) during early lactation compared with unaffected herdmates, and found that CM before a positive pregnancy diagnosis was associated with a significantly longer interval from calving to conception. This work was extended by Schrick et al. (2001), who confirmed this finding and reported that subclinical mastitis before first service was also associated with longer intervals to conception. Similar results were later found by several groups using similar approaches (Santos et al., 2004; Gunay and Gunay, 2008; Ahmadzadeh et al., 2009; Nava-Trujillo et al., 2010).

A major drawback of such an approach (i.e., comparison of a population of cows that experienced mastitis with a population that did not) is that it makes it difficult to account fully for factors potentially confounding the relationship between mastitis and fertility. For ex- 
ample, it is plausible that cows with higher milk yields are more likely to develop CM (Windig et al., 2005) and also more likely to have poor reproductive performance (Nebel and McGilliard, 1993). Alternative methods of data analysis better able to account for such factors include construction of stochastic statistical models to predict reproductive outcomes, with or without the inclusion of random effects terms to improve correction for unmeasured or unrecorded factors. Such techniques have been extensively used in this area, and studies have revealed associations between CM and increased odds of abortion (Risco et al., 1999), abnormal length interservice intervals (Moore et al., 1991), and failure to become pregnant after a service (Loeffler et al., 1999; Hertl et al., 2010). Other work has identified associations between subclinical mastitis as measured by increased individual-cow SCC (ICSCC) and increased odds of embryonic loss (Moore et al., 2005), abortion (Pinedo et al., 2009) and failure to become pregnant to first service (Pinedo et al., 2009).

Although convincing evidence exists that both CM and ICSCC can have negative associations with fertility, studies are lacking where the association between reproduction and both CM and ICSCC is explored. Furthermore, only the most recent work (Hertl et al., 2010) has evaluated the importance of the timing of CM in a sophisticated way, and this study was performed on a limited number of similar herds. Indeed, much of the work in this area has been carried out in intensively managed, high-producing herds in the United States, and it is unclear how the results of such studies generalize to production systems in other parts of the world with more modest outputs. Perhaps most importantly, the association between CM and ICSCC and the likelihood of a cow being served has not been thoroughly investigated. Early work in the field suggested that a detectable relationship existed, with cows experiencing early lactation CM showing increased calving-to-first service intervals compared with control cows (Barker et al., 1998; Schrick et al., 2001). More recent work has tended to focus on the associations between CM or ICSCC and the probability of pregnancy as a result of a given service. The current study, therefore, aims to evaluate the relationship between $\mathrm{CM}$ and subclinical mastitis and reproductive performance across a large number of UK dairy herds, using hierarchical discretetime survival modeling.

\section{MATERIALS AND METHODS}

\section{Data Collection and Restructuring}

A group of 20 veterinary surgeons throughout England and Wales were contacted to request copies of data sets from herds under their care that were considered to have a high standard of data recording. The veterinary surgeons within the group were practitioners acknowledged as having a special interest in performance monitoring in dairy herds. This represented a convenience sample, which was deemed appropriate, as high-quality data was required for analysis and it was not possible to acquire this using a true probabilistic sampling method.

Data sets were either from on-farm software, bureau recording services provided by veterinary practices, or from the central databases of national milk recording organizations. Data were anonymized and converted to a consistent database format. Data for lactations beginning in the years 1999 to 2008 were included in the study. Several data quality assessment criteria were then applied to each data set, with the aim of removing any herds where missing data or deficiencies in recording could affect the results. Measures included evaluation of incidence rate of and month-to-month variation in $\mathrm{CM}$ cases, and measurement of frequency and completeness of ICSCC recording. Quality of fertility data was evaluated using methods designed to detect events missing at random (such as the proportion of calvings for which a corresponding service was recorded and the lactational incidence rate of fertility events) or systematically (such as the apparent first-service pregnancy rate and the proportion of services that were the second of a pair between successive milk recording dates). Data quality auditing was applied at herd-year level, so that herds were only included in years where their data met the quality criteria. After removal of herds that failed to meet the inclusion criteria in any of the years examined, 105 herd data sets remained from the 468 initially submitted. Computational limits (maximum size of data set supported by the software used) determined that 80 data sets could be used for model building, and these were randomly selected from the 105. Basic statistics describing the 80 herds are provided in Table 1.

Herds were not excluded on the basis of predominant breed, although the vast majority of herds were mainly Holstein or Holstein-Friesian. No data regarding specific management practices in each herd (e.g., use of fixed time insemination and frequency of milking) was available. Clinical mastitis cases were diagnosed according to the normal practice of the herds.

Each data set was screened for duplicate event records (including records of multiple cases of CM within $7 \mathrm{~d}$ of each other, and services within $3 \mathrm{~d}$ of each other), and duplicate events removed. Further data quality audits were performed at the lactation level, and unsuitable lactations discarded (where there were insufficient milk-recording test days or where no service date 
Table 1. Descriptive statistics for the 80 herds used for model building ${ }^{1}$

\begin{tabular}{|c|c|c|c|c|c|c|c|c|}
\hline Parameter $^{2}$ & Mean & Minimum & \multicolumn{5}{|c|}{ Percentile } & Maximum \\
\hline Herd size & 209 & 48 & 105 & 133 & 176 & 232 & 339 & 672 \\
\hline Calving index (d) & 417 & 354 & 394 & 404 & 416 & 428 & 437 & 476 \\
\hline Culling rate $(\% / \mathrm{yr})$ & 22.1 & 11.5 & 15.9 & 18.8 & 21.7 & 24.5 & 28.2 & 42.8 \\
\hline IRCM (cases/cow-yr) & 0.55 & 0.15 & 0.23 & 0.34 & 0.50 & 0.70 & 0.90 & 1.37 \\
\hline
\end{tabular}

${ }^{1}$ For each herd, the mean value for each statistic was calculated over the time period for which that herd contributed data to the data set; the values in the table describe the distribution of these herd values.

${ }^{2} \mathrm{IRCM}=$ incidence rate of clinical mastitis (given in cases per cow-year at risk); BMSCC = bulk milk SCC, calculated from milk-recording data.

corresponding to the calving that ended the lactation was available). To facilitate construction of a discretetime survival model, data were then amalgamated and restructured into a format where each unit of data represented a 2-d risk period in every lactation between 20 and 220 DIM, such that each lactation could contribute a maximum of 100 units. Two alternative choices of risk period duration (20 and $2 \mathrm{~d}$ ) were evaluated and produced substantively similar results. The shorter risk period was chosen, as it allowed a more accurate and detailed assessment of the effect of timing of udder health events. Cows were censored after culling, death, sale, or pregnancy occurred.

Occurrence of a service was recorded as a binary event in each 2-d risk period, and occurrence of a cow becoming pregnant was calculated for each risk period. Pregnancy was determined to have occurred where a calving was recorded 266 to $296 \mathrm{~d}$ after a service; this range was designed to cover the normal range of gestation periods for the common dairy breeds and their crosses (McGuirk et al., 1998; 1999). For each risk period, several potential explanatory variables were also calculated; these are listed in Table 2. Clinical mastitis variables were binary (i.e., CM occurred or did not), with a separate code for ineligible (used when the CM variable referred to a time frame before the lactation began). Individual-cow SCC variables were grouped into 6 categories, as shown in Table 3, to explore the potential effect of magnitude of ICSCC as well as apparent presence or absence of an IMI as defined by a simple threshold. Categorizing the ICSCC variables also allowed retention in the data set of risk periods where no test day occurred in the time frame referred to by 1 or more of the ICSCC variables. Other categorical variables (such as parity and year) were recoded as necessary to avoid categories with very small numbers of risk periods: for example, the parity variable was recoded so that all animals of parity 5 or above were grouped into a single category. The final data set con- sisted of 2,338,025 risk periods from 39,590 lactations in 21,068 cows from 80 herds.

\section{Statistical Analysis}

Model 1: Probability of Pregnancy During a Risk Period and Potential Explanatory Variables. Discrete-time survival analysis was used to evaluate the association between the probability of a cow becoming pregnant in a given risk period and CM, ICSCC, and other potential explanatory variables (Yang and Goldstein, 2003). A 3-level hierarchical model was used to account for correlations within the data, with risk periods nested within cows nested within herds. A 4-level structure was also evaluated (with lactations within cows as an extra level), but was unsuitable because of the large proportion of cows that only contributed a single lactation; a fixed effect for parity was forced into the model to account for this. The model specification took the form

$$
\begin{gathered}
\text { Preg }_{\mathrm{tij}} \sim \operatorname{Bernoulli}\left(\text { mean }=\mu_{\mathrm{tij}}\right) \\
\ln \left(\frac{\mu_{\mathrm{tij}}}{1-\mu_{\mathrm{tij}}}\right)=\alpha+\beta_{1} \ln \operatorname{DIM}_{\mathrm{tij}}+\beta_{2}\left(\ln _{\mathrm{DIM}} \mathbf{t i j}^{2}\right. \\
+\boldsymbol{\beta}_{3} \mathbf{X}_{\mathrm{tij}}+\boldsymbol{\beta}_{4} \mathbf{X}_{\mathrm{ij}}+\boldsymbol{\beta}_{5} \mathbf{X}_{\mathrm{j}}+\mathrm{u}_{\mathrm{ij}}+\mathrm{v}_{\mathrm{j}}, \\
\mathrm{v}_{\mathrm{j}} \sim \text { normal distribution }\left(0, \sigma_{v}^{2}\right) \\
\mathrm{u}_{\mathrm{ij}} \sim \text { normal distribution }\left(0, \sigma_{u}^{2}\right),
\end{gathered}
$$

where $t$ represents a 2-d risk period and $i$ and $j$ the ith cow in the jth herd; $\mu_{\mathrm{tij}}$ is the fitted probability of Preg $_{\mathrm{tij}}$ (the outcome of the ith cow in the jth herd becoming pregnant during risk period $t)$; $\operatorname{lnDIM}_{\mathrm{tij}}$ is the natural logarithm of DIM at the beginning of risk period t; $\alpha$ is 
Table 2. Variables (with variable type) calculated at each level of data for each risk period

\begin{tabular}{|c|c|}
\hline Variable $^{1}$ & Variable type \\
\hline Served & Binary (served or not served) \\
\hline Becomes pregnant & Binary (becomes pregnant or does not) \\
\hline Season of risk period & Categorical (Jan-Mar, Apr-Jun, Jul-Sep, or Oct-Dec) \\
\hline CM 71-90 d after risk period & Binary (case of CM recorded or not) \\
\hline CM 57-70 d after risk period & Binary (case of CM recorded or not) \\
\hline CM 8-14 d after risk period & Binary (case of CM recorded or not) \\
\hline CM $1-7$ d after risk period & Binary (case of CM recorded or not) \\
\hline $\mathrm{CM}$ during risk period & Binary (case of CM recorded or not) \\
\hline CM $1-7 \mathrm{~d}$ before risk period & Binary plus $\mathrm{N} / \mathrm{A}^{2}$ (case of $\mathrm{CM}$ recorded or not) \\
\hline CM 8-14 d before risk period & Binary plus N/A (case of CM recorded or not) \\
\hline CM $15-28$ d before risk period & Binary plus N/A (case of CM recorded or not) \\
\hline ICSCC $31-60 \mathrm{~d}$ before risk period & Categorical—see Table 3 \\
\hline ICSCC $15-30 \mathrm{~d}$ before risk period & Categorical—see Table 3 \\
\hline ICSCC $8-14 \mathrm{~d}$ before risk period & Categorical-see Table 3 \\
\hline ICSCC $0-7 \mathrm{~d}$ before risk period & Categorical—see Table 3 \\
\hline ICSCC $1-30 \mathrm{~d}$ after risk period & Categorical—see Table 3 \\
\hline \multicolumn{2}{|l|}{ Lactation level } \\
\hline Year in which lactation began & Categorical (2003 or earlier, $2004,2005,2006,2007$, or 2008 ) \\
\hline Parity of cow & Categorical $(1,2,3,4$, or $>4)$ \\
\hline $\mathrm{CM}$ at $0-14 \mathrm{DIM}$ & Binary (case of CM recorded or not) \\
\hline 305 -d adjusted milk yield $(\times 1,000 \mathrm{~kg})$ & Continuous \\
\hline \multicolumn{2}{|l|}{ Herd level } \\
\hline Herd size & Continuous \\
\hline Herd cull and death rate & Continuous \\
\hline Herd average $305-\mathrm{d}$ adjusted milk yield $(\times 1,000 \mathrm{~kg})$ & Continuous \\
\hline
\end{tabular}

${ }^{1} \mathrm{CM}=$ clinical mastitis; ICSCC $=$ individual-cow SCC.

${ }^{2} \mathrm{~N} / \mathrm{A}$ category was used where the time frame to which the variable referred was outside of the lactation.

the regression intercept; $\beta_{1}$ and $\beta_{2}$ are the coefficients for the terms representing DIM; $\mathbf{X}_{\mathrm{tij}}$ is the vector of risk period-level covariates and $\boldsymbol{\beta}_{3}$ the corresponding vector of coefficients for covariates $\mathbf{X}_{\mathrm{tij}} ; \mathbf{X}_{\mathrm{ij}}$ is the vector of cow-level covariates and $\boldsymbol{\beta}_{4}$ the corresponding vector of coefficients for covariates $\mathbf{X}_{\mathrm{ij}} ; \mathbf{X}_{\mathrm{j}}$ is the vector of herdlevel covariates and $\boldsymbol{\beta}_{5}$ the corresponding vector of coefficients of covariates $\mathbf{X}_{\mathrm{j}}$; $\mathrm{u}_{\mathrm{ij}}$ is the random effect to reflect variation between individual cows; and $\mathrm{v}_{\mathrm{j}}$ is the random effect representing variation between herds, with $\sigma_{u}^{2}$ and $\sigma_{v}^{2}$ the variances of the normal distributions of the respective random effects terms.

Model building was carried out in MLwiN version 2.20 (Rasbash et al., 2010), using iterative generalized least squares (Rasbash et al., 2009) for initial parameter estimation. Final parameter estimates were then generated using Markov chain Monte Carlo (MCMC) with Gibbs sampling in MLwiN (Browne, 2009) using

Table 3. Categorization of individual cow SCC (cells $/ \mathrm{mL}$ ) explanatory variables

\begin{tabular}{lc}
\hline Category & Description \\
\hline 1 & $0-20,000$ \\
2 & $21,000-60,000$ \\
3 & $61,000-99,000$ \\
4 & $100,000-199,000$ \\
5 & $200,000-399,000$ \\
6 & $>399,000$ \\
N/A & Cow not eligible (time frame to which variable referred was outside \\
& of the lactation) or no milk recording within time frame \\
\hline
\end{tabular}


a burn-in chain length of 5,000 and monitoring chain length of at least 20,000 iterations. Diffuse prior distributions [functionally equivalent to a normal distribution with a very large variance for fixed parameters and a uniform distribution for scalar variances (Browne, 1998, 2009)] were specified for model parameters. Estimate traces for each parameter were visually assessed to ensure that satisfactory convergence had occurred. Use of MCMC for parameter estimation had the advantage of producing parameter estimates that are likely to be more reliable (Browne and Draper, 2006), as well as providing an indication (the deviance information criterion, DIC) of model fit (Spiegelhalter et al., 2002).

Initial model building was by forward selection: explanatory variables were added to the model one at a time (within the described model framework), and retained in the model if the $95 \%$ interval of highest posterior density (HPD) of the estimated coefficients for at least 1 of the variable's categories did not cover zero. Discarded variables were then individually reintroduced to the model, and retained if they satisfied the criteria described above. First-order interactions between explanatory variables were considered only if the interaction was held to be of potential clinical importance. This was considered important for model parsimony: inclusion of a large number of interaction terms could easily have led to a very complicated model, but one not giving any extra information that was likely to be of use in practice. None of the tested interaction terms were retained in this model. The possibility that the magnitude of associations between udder health and reproductive outcomes varied from herd to herd was also considered: this was represented by evaluating models with random slopes (Rasbash et al., 2009) for the udder health-related explanatory variables with the largest coefficients. This led to 2 candidate models: one including and one excluding random slopes. Of these, the model with the lowest DIC was selected (Spiegelhalter et al., 2002), a lower DIC representing a better combination of model fit and complexity. In this case, the model without random slopes was selected.

The potential for overparameterization in this type of model was recognized during the model selection process: relative magnitudes of the odds ratios (OR) for ICSCC variables (as these were considered to have the greatest potential for correlation) were compared with the patterns in the raw data, and found to be similar. Further evidence that overparameterization had been avoided was provided by the assessment of model fit using posterior predictions (see below), and the good convergence behavior of the MCMC chains during final parameter estimation.

Model 2: Probability of Pregnancy Conditional on a Service and Potential Explanatory Vari- ables. To improve understanding of the relationship between the outcome variable (probability of pregnancy during a given 2-d risk period) and the explanatory variables, a second model was constructed. The data set used to construct this model was a subset of the main data set described above, containing only risk periods where a service occurred (so that each unit of data represented a service). The outcome variable now represented the probability of a cow becoming pregnant to a given service. Model 2 took a similar form to that described in Equations 1 to 3, with the exception that a third- rather than a second-order polynomial term was required to represent stage of lactation. Model building was carried out as described for model 1.

Model Assumption Checking and Assessment of Model Fit. A simulation-based posterior prediction procedure was used to assess model fit (Gelman et al., 1996; Green et al., 2009). Posterior predictions were generated by simulation using WinBUGS version 1.4 (Spiegelhalter et al., 2002). For computational reasons, it was not possible to generate predictions for each risk period in the data set for model 1 , so subsets of 100,000 risk periods were randomly selected. As the data set for model 2 was substantially smaller, it was possible to use every unit of data in this data set to produce full posterior predictions from this model. Predictions were generated over 10,000 iterations, using the equation

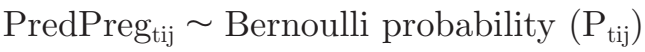

$$
\begin{aligned}
& \ln \left(\frac{\mathrm{P}_{\mathrm{tij}}}{1-\mathrm{P}_{\mathrm{tij}}}\right)=\alpha+\beta_{1} \ln \mathrm{DIM}_{\mathrm{tij}}+\beta_{2}\left(\ln \mathrm{DIM}_{\mathrm{tij}}\right)^{2} \\
& +\boldsymbol{\beta}_{3} \mathbf{X}_{\mathrm{tij}}+\boldsymbol{\beta}_{4} \mathbf{X}_{\mathrm{ij}}+\boldsymbol{\beta}_{5} \mathbf{X}_{\mathrm{j}}+\mathrm{u}_{\mathrm{ij}}+\mathrm{v}_{\mathrm{j}},
\end{aligned}
$$

where $\mathrm{P}_{\mathrm{tij}}$ is the predicted probability of a cow becoming pregnant during risk period $t$ in the ith cow in the jth herd, PredPreg ${ }_{\text {tij }}$ is a draw from a Bernoulli distribution with probability $\mathrm{P}_{\mathrm{tij}}$, and all other parameters are as described for Equations 1 to 3.

To assess model fit, units were grouped by variable or risk period (such as herd and parity of the cow, and stage of lactation and season of the risk period), and predictions summarized across the groups. The summary predictions were compared with the observed proportions of units in each group where a pregnancy occurred. The number of observations in each group varied from 438 (number of risk periods where $\mathrm{CM}$ occurred during the risk period in the 100,000 risk period subset used for predictions from model 1) to more than 10,000 (for example for each parity and season group). Where observed values fell outside the $95 \%$ credible interval for the predicted value, further investigation 
Table 4. Parameter estimates for cow becoming pregnant during a 2-d risk period (model 1)

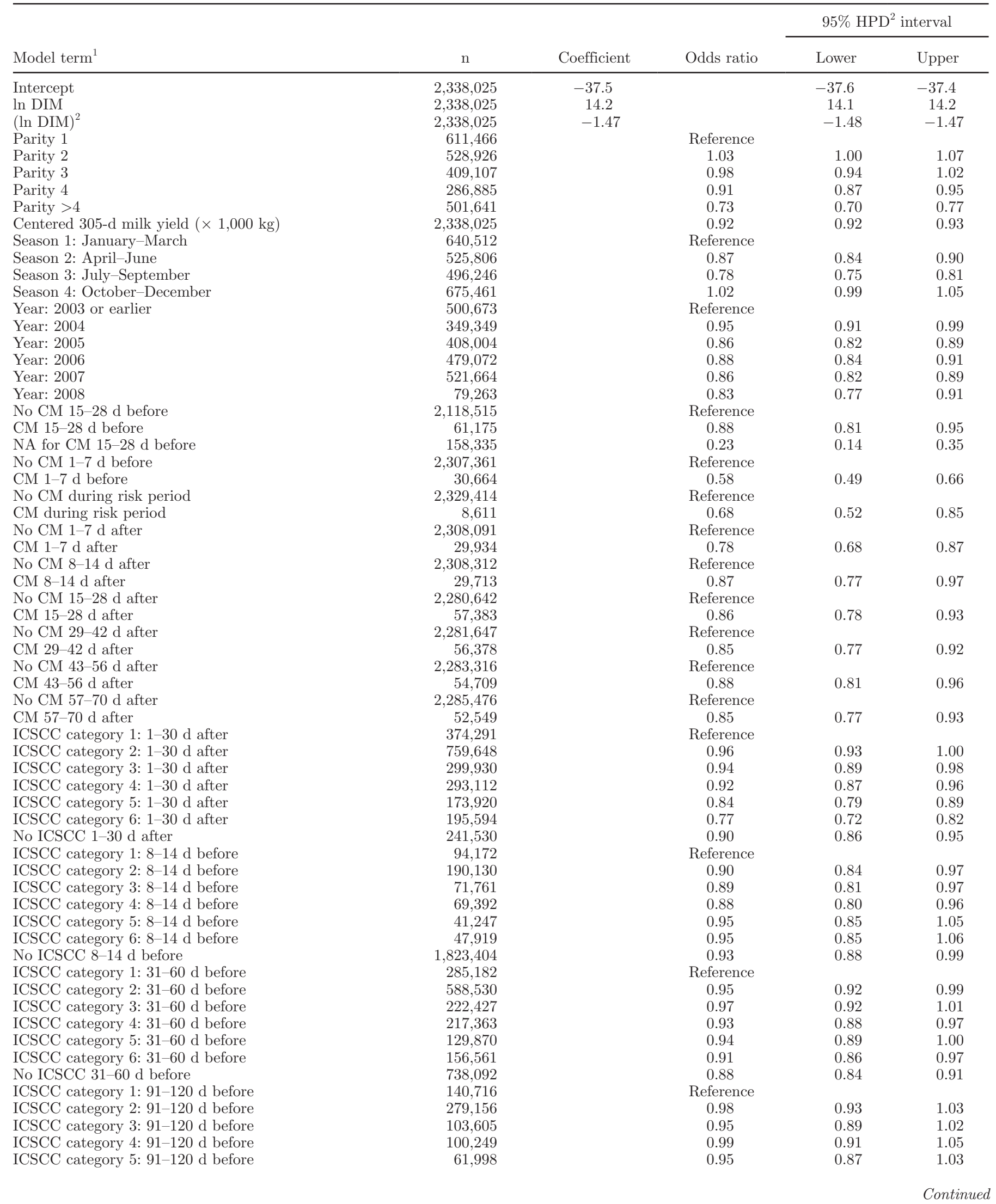


Table 4 (Continued). Parameter estimates for cow becoming pregnant during a 2-d risk period (model 1)

\begin{tabular}{|c|c|c|c|c|c|}
\hline \multirow[b]{2}{*}{ Model term ${ }^{1}$} & \multirow[b]{2}{*}{$\mathrm{n}$} & \multirow[b]{2}{*}{ Coefficient } & \multirow[b]{2}{*}{ Odds ratio } & \multicolumn{2}{|c|}{$95 \% \mathrm{HPD}^{2}$ interval } \\
\hline & & & & Lower & Upper \\
\hline No ICSCC 91-120 d before & $1,575,318$ & & 1.06 & 1.01 & 1.11 \\
\hline
\end{tabular}

${ }^{1} \mathrm{ln}=$ natural logarithm; $\mathrm{CM}=$ clinical mastitis; before $=$ before risk period; after $=$ after risk period; NA = not applicable $($ time frame to which variable referred was outside of the lactation or no milk recording within time frame); ICSCC $=$ individual-cow SCC (ICSCC categories: $1=$ 0 to 20,000 cells $/ \mathrm{mL} ; 2=21,000$ to 60,000 cells $/ \mathrm{mL} ; 3=61,000$ to 99,000 cells $/ \mathrm{mL} ; 4=100,000$ to 199,000 cells $/ \mathrm{mL} ; 5=200,000$ to 399,000 cells $/ \mathrm{mL} ; 6=>399,000$ cells $/ \mathrm{mL}$ ).

${ }^{2} \mathrm{HPD}=$ highest posterior density.

was instigated and steps taken to improve model fit in this region by restructuring of the covariate categories or investigation of interaction terms, so that for the final models the $95 \%$ credible interval for each group covered the observed proportion.

Posterior Predicted Relative Risks. To present results graphically as relative risks (which have a more intuitive interpretation than OR), further posterior predictions were carried out. These were performed using the method described above. Each udder health related variable was considered in turn. For binary explanatory variables (i.e., those relating to $\mathrm{CM}$ ), the subset of risk periods from the data set where the value of the explanatory variable was equal to 1 was selected. Predicted probability of pregnancy was calculated for each of these risk periods over 10,000 iterations as described in Equation 4. Predictions were then repeated with the value of the variable under consideration set to zero. For categorical predictor variables (i.e., those relating to ICSCC), the same process was followed for each category of the variable in turn. At each iteration, the total number of predicted pregnancies was calculated (SumPredPreg) where the variable was set to 1 and where it was set to zero. The predicted relative risk (PredRR) for each iteration was then calculated as shown in Equation 5:

$$
\text { PredRR }=\frac{\text { SumPredPreg }(\text { variable }=1)}{\text { SumPredPreg }(\text { variable }=0)} .
$$

The distributions of the predicted relative risks were summarized across the 10,000 iterations as medians and $95 \%$ credible intervals.

\section{RESULTS}

\section{Model 1}

A total of 29,237 pregnancies occurred during the 2,338,025 2-d risk periods under analysis. The mean probability of a pregnancy occurring during any given risk period was, therefore, 0.0125 : this would correspond to a probability of 0.131 of a cow becoming pregnant during a given 21-d period. A total of 10,096 of the 39,590 lactations $(0.255)$ contained at least 1 case of CM during the part of the lactation (i.e., 20-220 DIM) used for analysis.

Of the explanatory variables not directly related to udder health (i.e., those included as potential confounding factors), parity, season, year, and lactation 305-d milk yield were associated with the probability of a cow becoming pregnant during a risk period. The association between the outcome variable and lactation milk yield was negative (Table 4). Seasons 1 and 4 (October to March inclusive) were associated with higher probabilities of pregnancy than the summer months (April to September inclusive). Parities 1, 2, and 3 were not different from each other, but parities 4 and greater than 4 were associated with progressively lower probabilities of pregnancy occurring.

Parameter estimates for model 1 are shown in Table 4: estimates for OR were calculated by exponentiation of the estimate for each coefficient at each MCMC iteration and calculating the median value and area of 95\% HPD across all the iterations. Clinical mastitis was associated with the largest reduction in the probability of pregnancy when the case of CM was close to the 2-d risk period being evaluated; CM 1 to $7 \mathrm{~d}$ before the risk period had the lowest OR (indicating the largest reduction in the odds of the cow becoming pregnant at that risk period: $\mathrm{OR}=0.58,95 \% \mathrm{HPD}$ interval $0.49-0.66$ ) with $\mathrm{CM}$ during the risk period $(\mathrm{OR}=0.68,95 \% \mathrm{HPD}$ interval $0.52-0.85$ ) and $\mathrm{CM} 1$ to $7 \mathrm{~d}$ afterward (OR $=0.78,95 \%$ HPD interval $0.68-0.87$ ) the next lowest. The duration of time for which CM was associated with decreased risk of pregnancy was much greater after the risk period compared with before the risk period: a case of CM 57 to $70 \mathrm{~d}$ after the risk period was still associated with a decrease in risk of pregnancy at the risk period, whereas no such association was found for covariates relating to $\mathrm{CM}$ cases more than $28 \mathrm{~d}$ 


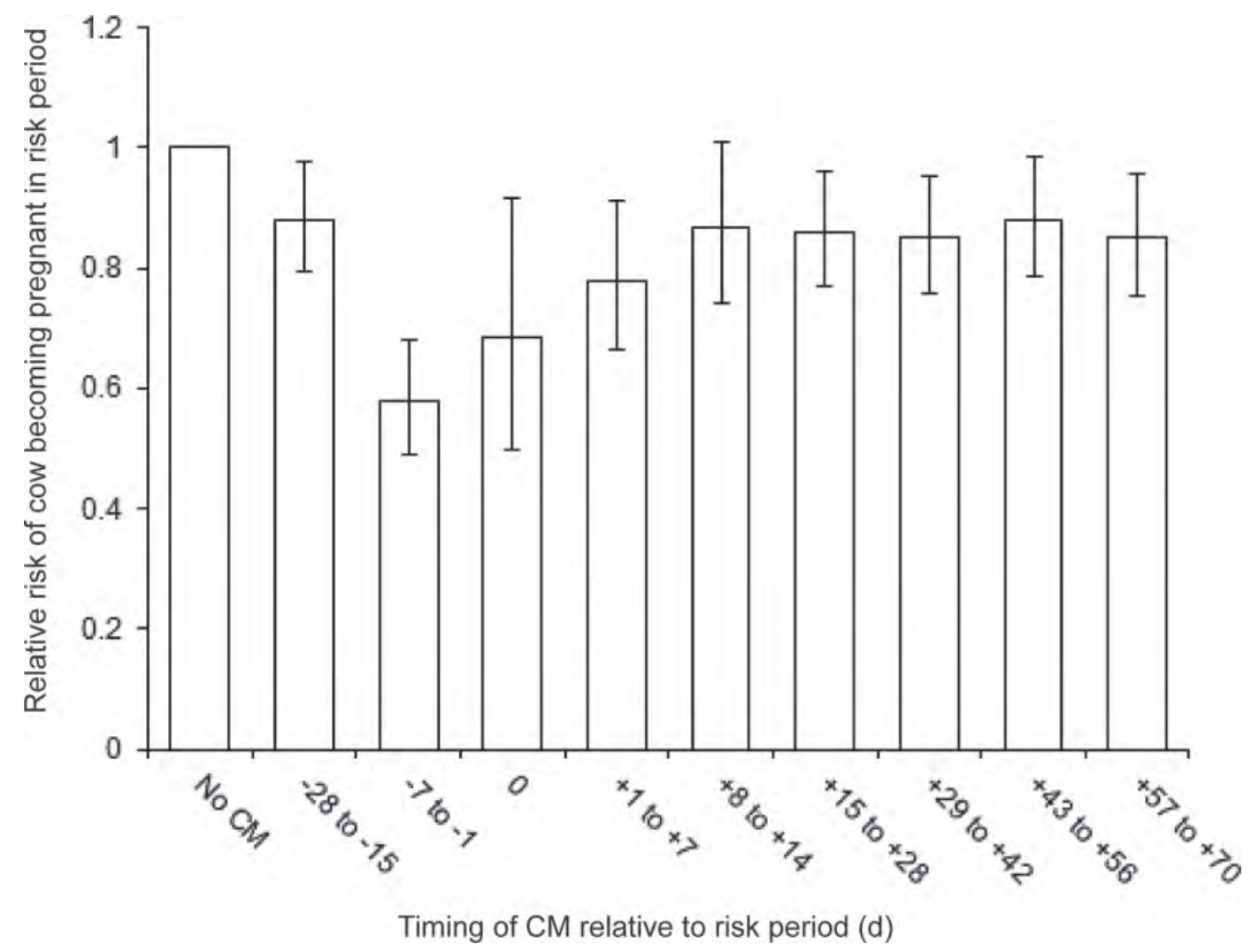

Figure 1. Association between the predicted relative risk of pregnancy at a given risk period and clinical mastitis (CM). Error bars represent the $95 \%$ credible interval for each predicted relative risk.

before the risk period. The magnitude of association between probability of pregnancy occurring during a risk period and the ICSCC variables was generally smaller than that with the CM variables, and generally increased in size with an increase in ICSCC categories (such that categories representing higher ICSCC values were generally associated with a greater decrease in the probability of pregnancy). These results are illustrated using posterior predictions of relative risks (accounting for the overall likelihood of pregnancy occurring during a risk period) in Figures 1 and 2 .

\section{Model 2}

A total of 85,482 services occurred in the data set: these formed the units of data for model 2. A total of 29,237 pregnancies resulted from these services: the overall pregnancy rate (i.e., the proportion of services that led to a pregnancy) was, therefore, $34.2 \%$. The median pregnancy rate at herd level was $35.8 \%$, with an interquartile range of 31.2 to $40.5 \%$.

Parameter estimates for model 2 are shown in Table 5. The associations between probability of pregnancy and the explanatory variables not directly related to udder health were very similar to those described for model 1. Broadly similar relationships with $\mathrm{CM}$ were also seen, although notably in this model, $\mathrm{CM}$ at the time of service had the largest negative association with the probability of a service leading to a pregnancy (OR $=0.68,95 \%$ HPD interval 0.51-0.91), followed by CM during the 1 to $7 \mathrm{~d}$ after the service $(\mathrm{OR}=0.72,95 \%$ HPD interval 0.62-0.84), with CM during the 1 to 7 $\mathrm{d}$ before the service having the third largest association $(\mathrm{OR}=0.75,95 \%$ HPD interval 0.63-0.89). Fewer ICSCC covariates were retained in model 2 compared with model 1: ICSCC recordings at 31 to $60 \mathrm{~d}$ before and 1 to $30 \mathrm{~d}$ after the service were the only timings that remained in the final model. Individual-cow SCC at 31 to $60 \mathrm{~d}$ before the risk period also showed a different relationship between ICSCC category and outcome: ICSCC categories 2 and 4 were associated with a lower probability of pregnancy compared with category 1 (the reference category), whereas categories 3, 5, and 6 were not different from category 1 . These results are summarized as predicted relative risks in Figures 3 and 4. 


\section{Model Checking}

The predicted probabilities of pregnancy for risk periods at different stages of lactation (generated using a subset of the data set and model 1) are shown in Figure 5, along with the observed proportion of risk periods at each stage where pregnancy occurred. The 95\% credible interval for the predicted probability at each stage is also shown, and covers the observed value at all points. Full posterior predictions for model 2 are demonstrated in a similar manner in Figure 6, showing predicted and observed pregnancy rates through lactation. The overall probability of a pregnancy occurring during a risk period (using model 1) and overall pregnancy rate (using model 2) were also predicted for each herd; in every case, the observed value for each herd fell within the $95 \%$ credible interval of the prediction for that herd.

To verify model fit further, predicted probabilities and observed proportions were also calculated for each parity and each season, lactations where yield was high (greater than $12,000 \mathrm{~kg}$ ) or low (less than $5,500 \mathrm{~kg}$ ), and for various categories of the CM and ICSCC vari- ables. In each case, the observed proportion of cases in which a pregnancy occurred lay within the coverage of the $95 \%$ credible interval for the model prediction. Therefore, posterior predictions suggested that model fit was good.

\section{DISCUSSION}

This study supports previous work in this field suggesting that both CM and ICSCC can have substantial associations with fertility performance. In terms of overall fertility performance (model 1), CM appeared to be associated with poorer reproductive outcomes over a wide span of time. A case of CM was associated with a lower probability of the cow becoming pregnant from 10 wk before the case to 4 wk afterward (with the exception of 8-14 d after the case, where no association was detected). A substantial-sized and additive relationship with subclinical mastitis (as measured by ICSCC) was also observed, although the sizes of these associations were generally smaller compared with those with CM at similar timing. Generally, recordings

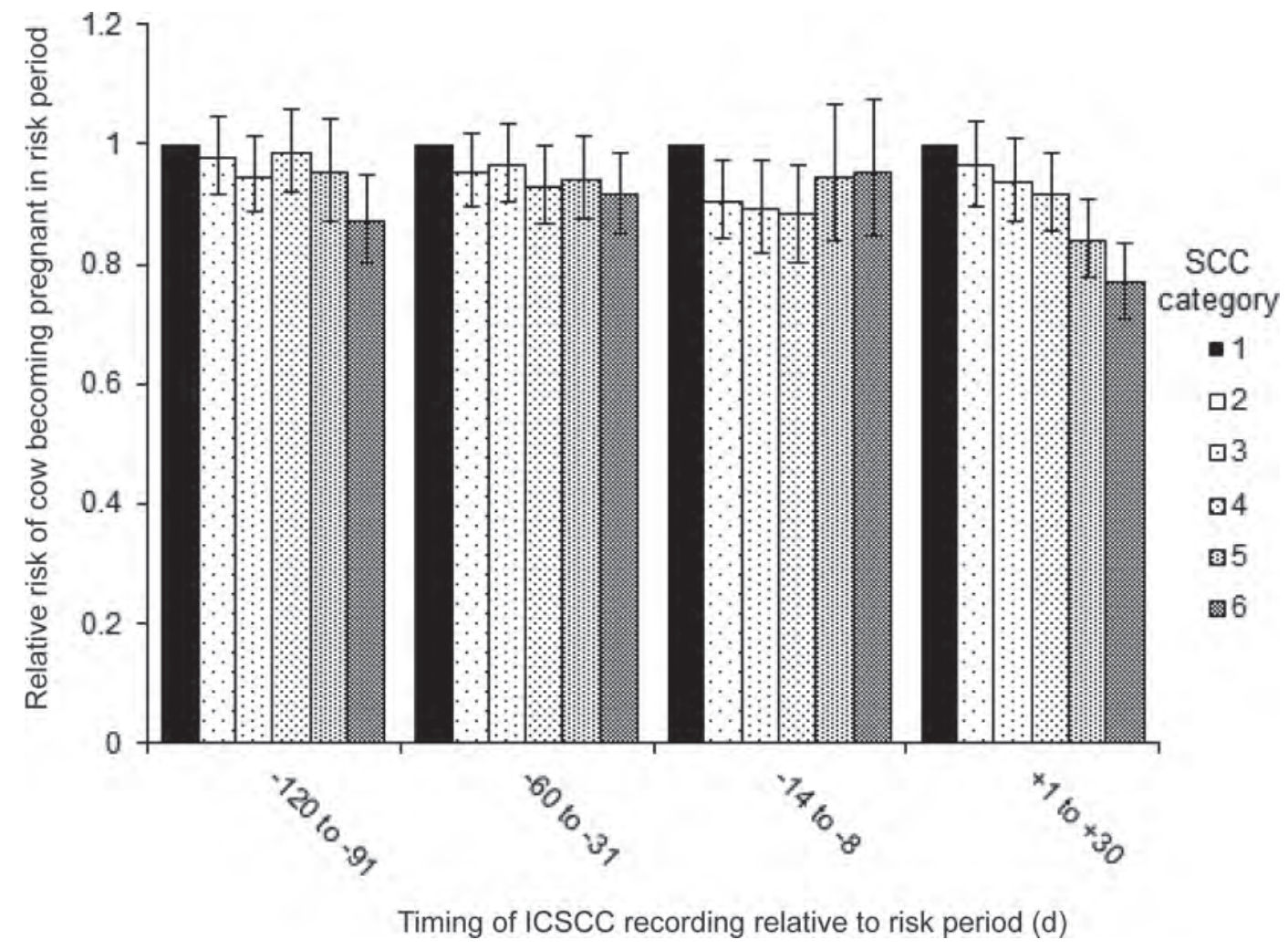

Figure 2. Association between the predicted relative risk of pregnancy at a given risk period and individual-cow SCC (ICSCC). Somatic cell count categories: $1=0$ to 20,000 cells $/ \mathrm{mL} ; 2=21,000$ to 60,000 cells $/ \mathrm{mL} ; 3=61,000$ to 99,000 cells $/ \mathrm{mL} ; 4=100,000$ to 199,000 cells $/ \mathrm{mL} ; 5=$ 200,000 to 399,000 cells/mL; $6=>399,000$ cells $/ \mathrm{mL}$. Error bars represent the $95 \%$ credible interval for each predicted relative risk. 
Table 5. Parameter estimates for a cow becoming pregnant as a result of a given service (model 2)

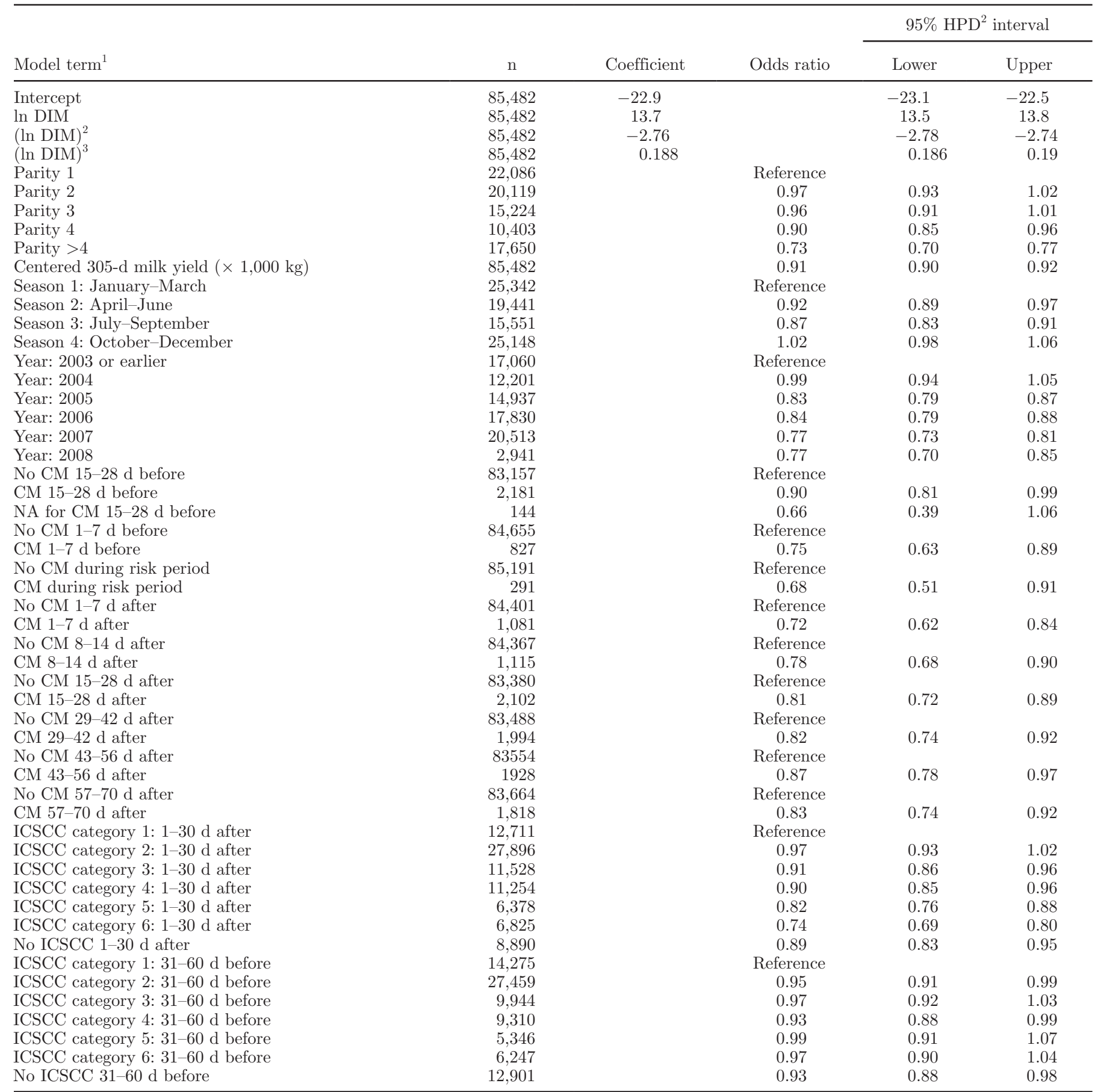

${ }^{1} \ln =$ natural logarithm; $\mathrm{CM}=$ clinical mastitis; before = before risk period; after $=$ after risk period; NA = not applicable (time frame to which variable referred was outside of the lactation or no milk recording within time frame); ICSCC $=$ individual-cow SCC (ICSCC categories: $1=$ 0 to 20,000 cells $/ \mathrm{mL} ; 2=21,000$ to 60,000 cells $/ \mathrm{mL} ; 3=61,000$ to 99,000 cells $/ \mathrm{mL} ; 4=100,000$ to 199,000 cells $/ \mathrm{mL} ; 5=200,000$ to 399,000 cells $/ \mathrm{mL} ; 6=>399,000$ cells $/ \mathrm{mL})$.

${ }^{2} \mathrm{HPD}=$ highest posterior density. 


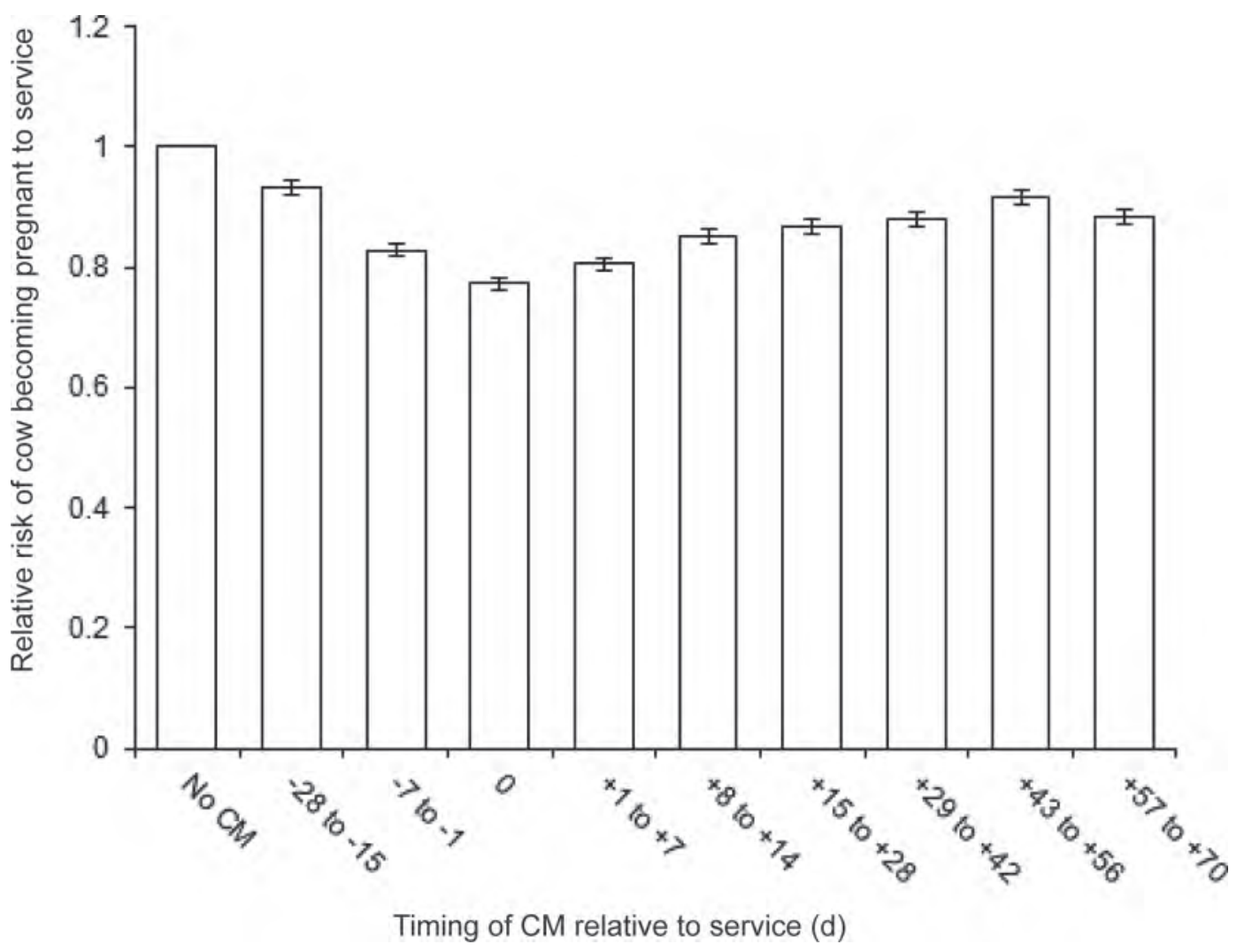

Figure 3. Association between the predicted relative risk of pregnancy at a given service and clinical mastitis (CM). Error bars represent the $95 \%$ credible interval for each predicted relative risk.

in higher SCC categories tended to be associated with decreased reproductive performance.

Having found associations between CM and ICSCC variables and overall reproductive performance, model 2 was constructed in an attempt to improve understanding of how these associations were mediated. Reproductive performance is effectively dependent on 2 factors: the likelihood of an eligible cow being served (which depends on factors such as expression and detection of estrus, and postparturient return to ovarian cyclicity) and the likelihood that a service will lead to a pregnancy (the pregnancy rate). Therefore, the construction of a second model in which the outcome represented pregnancy rate was useful.

The same CM-related variables were retained in model 2 as model 1, so the same timings of CM were associated with decreased pregnancy rate as with reduced overall fertility performance. However, a difference was observed in the relative magnitudes of associations between outcome and the various CM variables in model 1 compared with model 2 . In model $2, \mathrm{CM}$ at the time of service was associated with the largest reduction in pregnancy rate, with a generally decreasing magnitude of effect size for timings of CM up to $70 \mathrm{~d}$ postservice.
In model 1, the largest association was seen where CM occurred at 1 to $7 \mathrm{~d}$ before the risk period, with a smaller association with CM during the risk period, and a broadly decreasing effect size of CM variables further in the future. This suggests that a major component of the association between CM 1 to $7 \mathrm{~d}$ earlier and the chance of a cow becoming pregnant is a decreased chance of her being served. This could clearly be as a result of management decisions not to serve a cow that had recently had a case of CM, but could also be related to suppression of ovulation or expression of estrus in cows that have recently had CM. If heats where the cow was not served were recorded accurately in the data set, it would be possible to distinguish between these possibilities, but such events are rarely recorded consistently in UK herds.

No previous work has accurately evaluated the importance of timing on the associations between udder health and overall reproductive performance; recent existing work in this field has tended to focus on pregnancy rate (proportion of services leading to a pregnancy) as an outcome. The results of this study support previous work that suggested that CM in the period shortly before and shortly after first service has a negative 


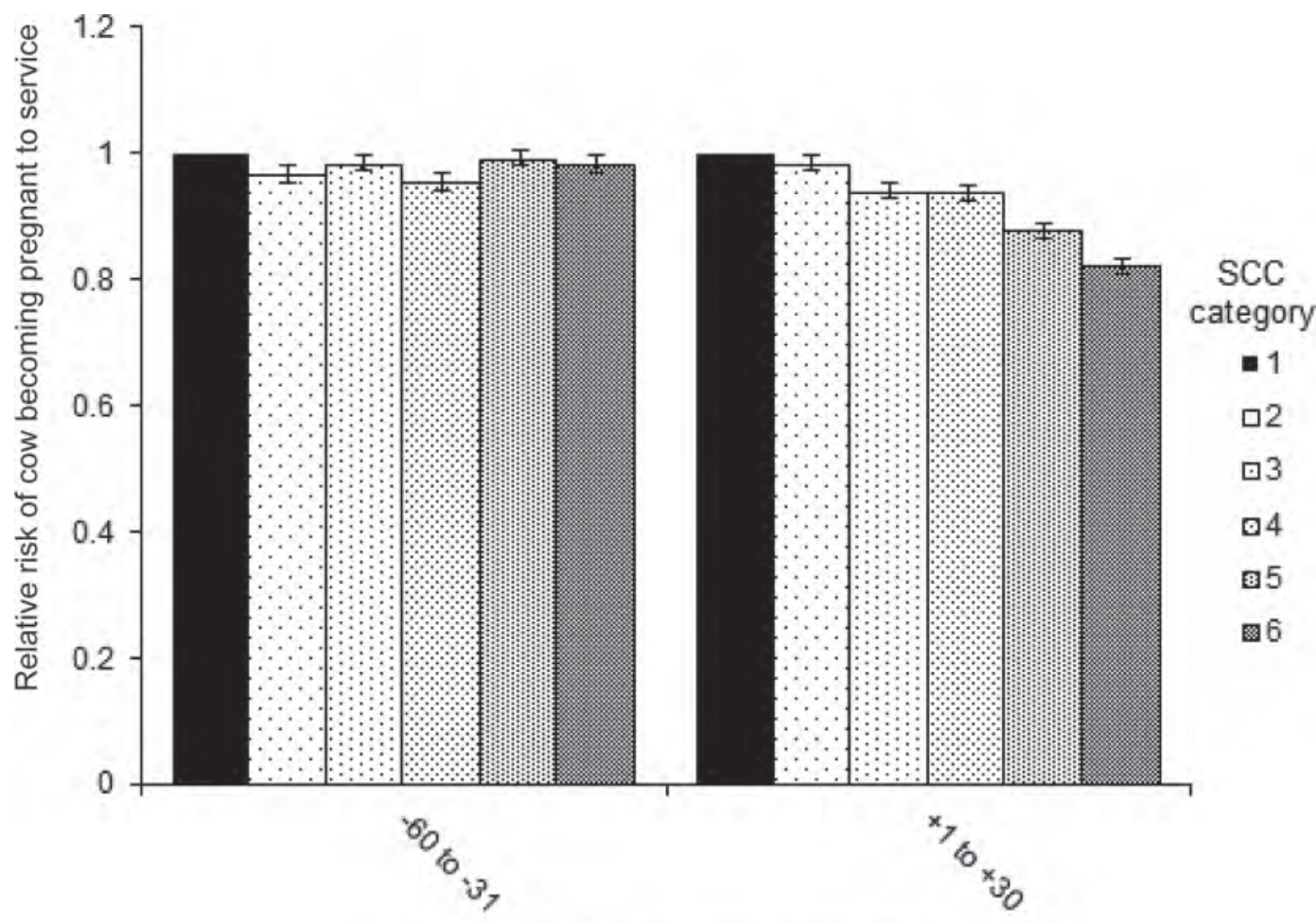

Timing of ICSCC recording relative to service (d)

Figure 4. Association between the predicted relative risk of pregnancy at a given service and individual-cow SCC (ICSCC). Somatic cell count categories: $1=0$ to 20,000 cells $/ \mathrm{mL} ; 2=21,000$ to 60,000 cells $/ \mathrm{mL} ; 3=61,000$ to 99,000 cells $/ \mathrm{mL} ; 4=100,000$ to 199,000 cells $/ \mathrm{mL} ; 5=$ 200,000 to 399,000 cells $/ \mathrm{mL} ; 6=>399,000$ cells/mL. Error bars represent the $95 \%$ credible interval for each predicted relative risk.

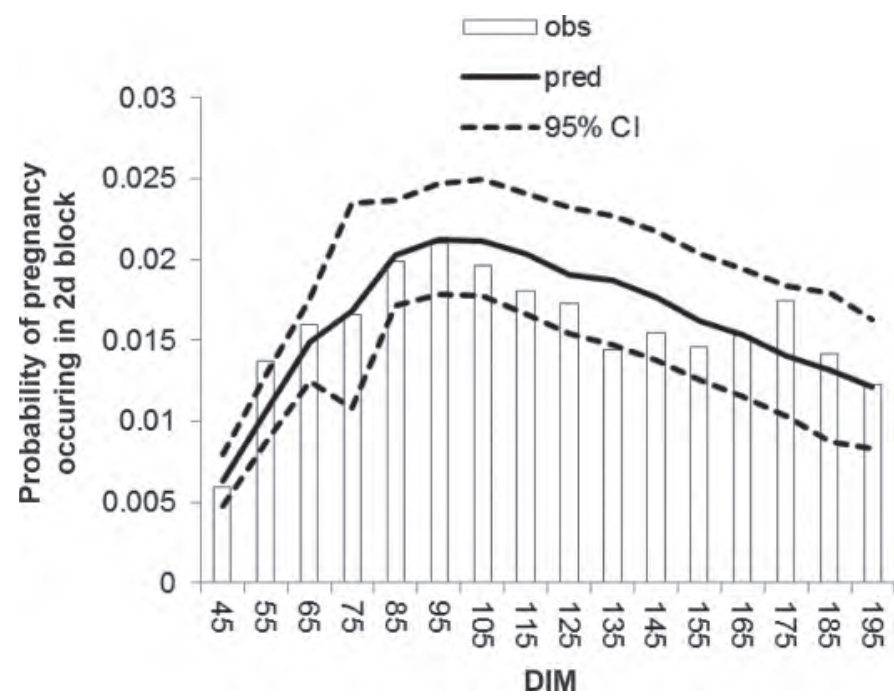

Figure 5. Predicted probability of pregnancy occurring during a 2-d risk period (with $95 \%$ credible interval, CI) by DIM, also showing observed proportion of risk periods in which a pregnancy occurred. Posterior predictions were generated from a subset of approximately 100,000 units from the whole data set. Obs = observed proportion of risk periods where pregnancy occurred; pred $=$ predicted probability of pregnancy occurring during a risk period.

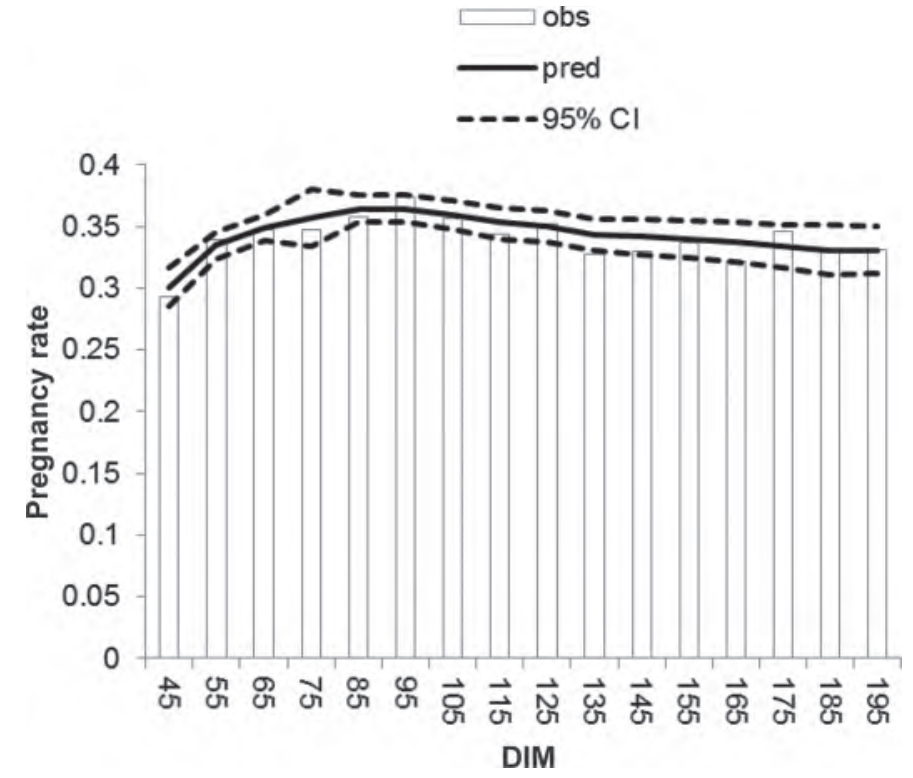

Figure 6. Predicted probability of pregnancy occurring to a given service (with $95 \%$ credible interval, CI) by DIM, also showing observed proportion of services leading to a pregnancy (pregnancy rate). Full posterior predictions were generated from the whole data set. Obs = observed proportion of services where pregnancy occurred; pred $=$ predicted probability of pregnancy occurring after service. 
relationship with fertility (Barker et al., 1998; Schrick et al., 2001; Santos et al., 2004; Gunay and Gunay, 2008). The current study has shown a slightly longer duration of association between CM and reproductive performance compared with most existing research. Previous work evaluating overall fertility (as opposed to pregnancy rate) as an outcome has tended to categorize CM as occurring before first service, between first service and pregnancy diagnosis, or after a positive pregnancy diagnosis (Barker et al., 1998; Schrick et al., 2001). Previous studies have tended not to reveal a significant difference in the CM after pregnancy diagnosis group compared with cows with no CM during lactation. This could be because this crude categorization of the timing of $\mathrm{CM}$ would group together $\mathrm{CM}$ cases at any stage of lactation after pregnancy diagnosis, thus including cases at the end of lactation (which would be unlikely to exert any influence of fertility) in the same category as cases as early as $28 \mathrm{~d}$ after the first service. This could tend to mask the effect of CM in the period around and shortly after the stage at which pregnancy diagnosis is commonly undertaken. Alternatively, it is possible that grouping lactations in this way and comparing reproductive performance at lactation level between groups fails to account for confounding variables, which may suppress the relationship between $\mathrm{CM}$ and fertility.

The associations revealed between subclinical mastitis and overall reproductive performance also broadly support earlier work and provide novel information regarding the importance of the timing of subclinical mastitis. Schrick et al. (2001) demonstrated an extended calving-to-conception interval in cows that had subclinical mastitis (diagnosed by bacteriological sampling) before first service, but found no significant effect of subclinical mastitis either between first service and positive pregnancy diagnosis or later in lactation. The current study used ICSCC as a proxy for infection status, and as occurrences of $\mathrm{CM}$ are also included in the model, the apparent effects of ICSCC will represent the association between subclinical mastitis and reproductive outcome. In contrast to Schrick et al. (2001), the current study found an association between reproductive performance and ICSCC status in the month following the risk period. In fact, ICSCC at this time had the largest association with reproductive performance compared with any timing of ICSCC before the risk period.

The results of model 2 provide support for existing work demonstrating an association between CM or subclinical mastitis and decreased pregnancy rate (Moore et al., 1991; Loeffler et al., 1999; Perrin et al., 2007; Gunay and Gunay, 2008; Ahmadzadeh et al., 2009; Pinedo et al., 2009; Hertl et al., 2010). This is the first study to specifically examine the effect of timing of subclinical mastitis relative to service, and interestingly demonstrated that subclinical mastitis present at between 1 and $30 \mathrm{~d}$ postservice was associated with the largest decrease in pregnancy rate. As might be expected, the magnitude of the relationship tended to increase with increasing ICSCC. The odds of a service leading to a pregnancy were decreased by around $18 \%$ where an ICSCC of between 200,000 and 399,000 cells/mL was recorded at $<31 \mathrm{~d}$ postservice, whereas the odds were decreased by almost $26 \%$ when the ICSCC was $>399,000$ cells $/ \mathrm{mL}$. The magnitudes of these relationships are comparable with those with $\mathrm{CM}$ very close to the service date; only $\mathrm{CM}$ at the time of service was associated with a much greater decrease in pregnancy rate. This provides evidence that subclinical mastitis as well as CM has a clinically significant relationship with reproductive outcome.

Several potential mechanisms have been proposed to explain the effect of udder health on reproductive performance. These are comprehensively reviewed by Hansen et al. (2004), but broadly encompass detrimental impact of inflammatory mediators on ovarian follicular function (Herath et al., 2007; Williams et al., 2008), intrauterine embryonic survival (Soto et al., 2003), and the balance of luteolytic versus luteotrophic prostaglandins postconception (Hockett et al., 2000; Neuvians et al., 2004). Thus, mechanisms exist to explain the effect of IMI both before and after the risk period or service on the probability of establishment of pregnancy. In this study, IMI before service was generally associated with a smaller effect on fertility, suggesting that effects on oocyte quality are perhaps less important compared with the other suggested mechanisms.

One of the drawbacks of the approach taken in this study was the sampling strategy used to collect data. Where nonprobability sampling techniques are used, it is important to be cautious in generalizing from the results of the research to the wider population. In this case, strong sampling bias toward herds with betterkept records was present. It is plausible that such herds will, for example, tend to be larger, more carefully managed and more intensive in production compared with the population of UK dairy herds as a whole (and, therefore, will not constitute a representative sample). However, it is important to view this in a biological as well as a statistical context: this study aimed to evaluate the associations between udder health and reproductive performance at cow level. Although these relationships may be different in different types of herd, differences at cow level are likely to be smaller.

This study has provided more robust and detailed evidence to support existing work in the field. A sizeable body of work examining the potential mechanisms 
by which udder health could affect dairy cow fertility already exists, and this may be useful in determining the value of research into methods to minimize these effects by therapeutic or other means. A second implication of better understanding of the association between udder health and reproduction is the opportunity for clearer insight into the impact of this at herd level. Application of the results of this study at herd level is not straightforward, and would benefit from further investigation in the future, possibly using a simulationbased approach.

\section{CONCLUSIONS}

This study demonstrates clear associations between both $\mathrm{CM}$ and subclinical mastitis and depressed reproductive performance. Intramammary infections appear to have a negative but variable relationship with cow fertility over a very long period of time, and subclinical mastitis can, in some situations, have a magnitude of relationship size similar to CM. This provides extra impetus to implement strategies to control mastitis at herd level as well as giving greater insight into factors affecting fertility.

\section{REFERENCES}

Ahmadzadeh, A., F. Frago, B. Shafii, J. C. Dalton, W. J. Price, and M. A. McGuire. 2009. Effect of clinical mastitis and other diseases on reproductive performance of Holstein cows. Anim. Reprod. Sci. 112:273-282.

Barker, A. R., F. N. Schrick, M. J. Lewis, H. H. Dowlen, and S. P. Oliver. 1998. Influence of clinical mastitis during early lactation on reproductive performance of Jersey cows. J. Dairy Sci. $81: 1285-1290$.

Bradley, A. J., K. A. Leach, J. E. Breen, L. E. Green, and M. J. Green. 2007. Survey of the incidence and aetiology of mastitis on dairy farms in England and Wales. Vet. Rec. 160:253-257.

Browne, W. J. 1998. Applying MCMC methods to multilevel models. $\mathrm{PhD}$ Thesis. University of Bath, Bath, UK.

Browne, W. J. 2009. MCMC Estimation in MLwiN v2.20. Centre for Multilevel Modelling, University of Bristol, Bristol, UK.

Browne, W. J., and D. Draper. 2006. A comparison of Bayesian and likelihood-based methods for fitting multilevel models. Bayesian Anal. 1:473-513.

Esslemont, R. J. 2003. The costs of poor fertility and what to do about reducing them. Cattle Pract. 11:237-250.

Esslemont, R. J., and M. Kossaibati. 2002. DAISY Research Report No. 5: The costs of poor fertility and disease in UK dairy herdsTrends in DAISY herds over 10 seasons. University of Reading, UK.

Gelman, A., X. L. Meng, and H. Stern. 1996. Posterior predictive assessment of model fitness via realized discrepancies. Statist. Sinica 6:733-760.

González-Recio, O., M. A. Pérez-Cabal, and R. Alenda. 2004. Economic value of female fertility and its relationship with profit in Spanish dairy cattle. J. Dairy Sci. 87:3053-3061.

Green, M. J., G. F. Medley, and W. J. Browne. 2009. Use of posterior predictive assessments to evaluate model fit in multilevel logistic regression. Vet. Res. 40:30.

Gunay, A., and U. Gunay. 2008. Effects of clinical mastitis on reproductive performance in Holstein cows. Acta Vet. (Brno) 77:555560 .
Hansen, P. J., P. Soto, and R. P. Natzke. 2004. Mastitis and fertility in cattle-Possible involvement of inflammation or immune activation in embryonic mortality. Am. J. Reprod. Immunol. 51:294301.

Herath, S., E. J. Williams, S. T. Lilly, R. Gilbert, H. Dobson, C. E. Bryant, and I. M. Sheldon. 2007. Ovarian follicular cells have innate immune capabilities that modulate their endocrine function. Reproduction 134:683-693.

Hertl, J. A., Y. T. Grohn, J. D. G. Leach, D. Bar, G. J. Bennett, R. N. Gonzalez, B. J. Rauch, F. L. Welcome, L. W. Tauer, and Y. H. Schukken. 2010. Effects of clinical mastitis caused by grampositive and gram-negative bacteria and other organisms on the probability of conception in New York State Holstein dairy cows. J. Dairy Sci. 93:1551-1560.

Hockett, M. E., F. M. Hopkins, M. J. Lewis, A. M. Saxton, H. H. Dowlen, S. P. Oliver, and F. N. Schrick. 2000. Endocrine profiles of dairy cows following experimentally induced clinical mastitis during early lactation. Anim. Reprod. Sci. 58:241-251.

Hudson, C. D., J. E. Breen, A. J. Bradley, and M. J. Green. 2010. Fertility in UK dairy herds: Preliminary findings of a large-scale study. Cattle Pract. 18:89-94

Kemp, M. H., A. M. Nolan, P. J. Cripps, and J. L. Fitzpatrick. 2008. Animal-based measurements of the severity of mastitis in dairy cows. Vet. Rec. 163:175-179.

LeBlanc, S. 2007. Economics of improving reproductive performance in dairy herds. Adv. Dairy Technol. 19:201-214.

Loeffler, S. H., M. J. de Vries, and Y. H. Schukken. 1999. The effects of time of disease occurrence, milk yield, and body condition on fertility in dairy cows. J. Dairy Sci. 82:2589-2604.

McGuirk, B. J., I. Going, and A. R. Gilmour. 1998. The genetic evaluation of beef sires used for crossing with dairy cows in the UK 1. Sire breed and non-genetic effects on calving survey traits. Anim. Sci. 66:35-45.

McGuirk, B. J., I. Going, and A. R. Gilmour. 1999. The genetic evaluation of UK Holstein Friesian sires for calving ease and related traits. Anim. Sci. 68:413-422.

Moore, D. A., J. S. Cullor, R. H. Bondurant, and W. M. Sischo. 1991. Preliminary field evidence for the association of clinical mastitis with altered interestrus intervals in dairy cattle. Theriogenology $36: 257-265$.

Moore, D. A., M. W. Overton, R. C. Chebel, M. L. Truscott, and R. H. BonDurant. 2005. Evaluation of factors that affect embryonic loss in dairy cattle. J. Am. Vet. Med. Assoc. 226:1112-1118.

Nava-Trujillo, H., E. Soto-Belloso, and A. E. Hoet. 2010. Effects of clinical mastitis from calving to first service on reproductive performance in dual-purpose cows. Anim. Reprod. Sci. 121:12-16.

Nebel, R. L., and M. L. McGilliard. 1993. Interactions of high milk yield and reproductive performance in dairy cows. J. Dairy Sci. 76:3257-3268.

Neuvians, T. P., D. Schams, B. Berisha, and M. W. Pfaffl. 2004. Involvement of pro-inflammatory cytokines, mediators of inflammation, and basic fibroblast growth factor in prostaglandin $\mathrm{F}_{2 \alpha^{-}}$ induced luteolysis in bovine corpus luteum. Biol. Reprod. 70:473480.

Perrin, L., R. W. Bostelmann, and I. M. Sheldon. 2007. Reduced conception rates associated with bovine mastitis during a 'window of opportunity'. Vet. Rec. 161:61-62.

Pinedo, P. J., P. Melendez, J. A. Villagomez-Cortes, and C. A. Risco. 2009. Effect of high somatic cell counts on reproductive performance of Chilean dairy cattle. J. Dairy Sci. 92:1575-1580.

Rasbash, J., C. Charlton, W. J. Browne, M. Healy, and B. Cameron. 2010. MLwiN Version 2.2. Centre for Multilevel Modelling, University of Bristol, Bristol, UK.

Rasbash, J., F. Steele, W. J. Browne, and H. Goldstein. 2009. A User's Guide to MLwiN, v2.10. Centre for Multilevel Modelling, University of Bristol, Bristol, UK.

Risco, C. A., G. A. Donovan, and J. Hernandez. 1999. Clinical mastitis associated with abortion in dairy cows. J. Dairy Sci. 82:16841689

Santos, J. E. P., R. L. A. Cerri, M. A. Ballou, G. E. Higginbotham, and J. H. Kirk. 2004. Effect of timing of first clinical mastitis oc- 
currence on lactational and reproductive performance of Holstein dairy cows. Anim. Reprod. Sci. 80:31-45.

Schrick, F. N., M. E. Hockett, A. M. Saxton, M. J. Lewis, H. H. Dowlen, and S. P. Oliver. 2001. Influence of subclinical mastitis during early lactation on reproductive parameters. J. Dairy Sci. 84:1407-1412.

Soto, P., R. P. Natzke, and P. J. Hansen. 2003. Identification of possible mediators of embryonic mortality caused by mastitis: Actions of lipopolysaccharide, prostaglandin $\mathrm{F}_{2 \alpha}$ and the nitric oxide generator, sodium nitroprusside dihydrate, on oocyte maturation and embryonic development in cattle. Am. J. Reprod. Immunol. $50: 263-272$.

Spiegelhalter, D. J., N. G. Best, B. R. Carlin, and A. van der Linde. 2002. Bayesian measures of model complexity and fit. J. R. Stat. Soc. Series B Stat. Methodol. 64:583-639.
Williams, E. J., K. Sibley, A. N. Miller, E. A. Lane, J. Fishwick, D. M. Nash, S. Herath, G. C. W. England, H. Dobson, and I. M. Sheldon. 2008. The effect of Escherichia coli lipopolysaccharide and tumour necrosis factor alpha on ovarian function. Am. J. Reprod. Immunol. 60:462-473.

Windig, J. J., M. P. L. Calus, and R. F. Veerkamp. 2005. High milk yields and the risk of mastitis in different herd environments. Pages 254-259 in Mastitis in Dairy Production-Current Knowledge and Future Ideas: Proceedings of the 4th IDF International Mastitis Conference. Wageningen Academic Publishers, Maastricht, the Netherlands.

Yang, M., and H. Goldstein. 2003. Modelling survival data in MLwiN 1.20. Centre for Multilevel Modelling, University of Bristol, Bristol, UK. 